University of Nebraska - Lincoln

DigitalCommons@University of Nebraska - Lincoln

\title{
The role of demographic compensation theory in incidental take assessments for endangered species
}

\author{
Conor P. McGowan \\ University of Missouri, cmcgowan@usgs.gov \\ Mark R. Ryan \\ University of Missouri, RyanMR@missouri.edu \\ Michael C. Runge \\ USGS Patuxent Wildlife Research Center, mrunge@usgs.gov \\ Joshua J. Millspaugh \\ University of Missouri, joshua.millspaugh@umontana.edu \\ Jean Fitts Cochrane \\ USGS - Patuxent Wildlife Research Center
}

Follow this and additional works at: https://digitalcommons.unl.edu/usgsstaffpub

Part of the Geology Commons, Oceanography and Atmospheric Sciences and Meteorology Commons, Other Earth Sciences Commons, and the Other Environmental Sciences Commons

McGowan, Conor P.; Ryan, Mark R.; Runge, Michael C.; Millspaugh, Joshua J.; and Cochrane, Jean Fitts, "The role of demographic compensation theory in incidental take assessments for endangered species" (2011). USGS Staff -- Published Research. 555.

https://digitalcommons.unl.edu/usgsstaffpub/555

This Article is brought to you for free and open access by the US Geological Survey at DigitalCommons@University of Nebraska - Lincoln. It has been accepted for inclusion in USGS Staff -- Published Research by an authorized administrator of DigitalCommons@University of Nebraska - Lincoln. 


\title{
The role of demographic compensation theory in incidental take assessments for endangered species
}

\author{
Conor P. McGowan ${ }^{\mathrm{a}, \mathrm{b}, *}$, Mark R. Ryan ${ }^{\mathrm{a}}$, Michael C. Runge ${ }^{\mathrm{b}}$, Joshua J. Millspaugh ${ }^{\mathrm{a}}$, Jean Fitts Cochrane ${ }^{\mathrm{b}, 1}$ \\ a Department of Fisheries and Wildlife Sciences, 302 Anheuser Busch Natural Resources Bldg., University of Missouri, Columbia, MO 65211, United States \\ ${ }^{\mathrm{b}}$ USGS - Patuxent Wildlife Research Center, 12100 Beech Forest Rd., Laurel, MD 20708, United States
}

\section{A R T I C L E I N F O}

\section{Article history:}

Received 7 May 2010

Received in revised form 13 October 2010

Accepted 28 October 2010

Available online 8 January 2011

\section{Keywords:}

Endangered species

Compensation

Piping plover

Charadrius melodus

Population modeling

\begin{abstract}
A B S T R A C T
Many endangered species laws provide exceptions to legislated prohibitions through incidental take provisions as long as take is the result of unintended consequences of an otherwise legal activity. These allowances presumably invoke the theory of demographic compensation, commonly applied to harvested species, by allowing limited harm as long as the probability of the species' survival or recovery is not reduced appreciably. Demographic compensation requires some density-dependent limits on survival or reproduction in a species' annual cycle that can be alleviated through incidental take. Using a population model for piping plovers in the Great Plains, we found that when the population is in rapid decline or when there is no density dependence, the probability of quasi-extinction increased linearly with increasing take. However, when the population is near stability and subject to density-dependent survival, there was no relationship between quasi-extinction probability and take rates. We note however, that a brief examination of piping plover demography and annual cycles suggests little room for compensatory capacity. We argue that a population's capacity for demographic compensation of incidental take should be evaluated when considering incidental allowances because compensation is the only mechanism whereby a population can absorb the negative effects of take without incurring a reduction in the probability of survival in the wild. With many endangered species there is probably little known about density dependence and compensatory capacity. Under these circumstances, using multiple system models (with and without compensation) to predict the population's response to incidental take and implementing follow-up monitoring to assess species response may be valuable in increasing knowledge and improving future decision making.
\end{abstract}

Published by Elsevier Ltd.

\section{Introduction}

Endangered species laws of industrialized nations typically prohibit the killing, harassment, or habitat destruction of any species protected under those laws, yet also allow for some exception to those prohibitions under 'incidental taking' allowances. Under the United States' Endangered Species Act (US-ESA), for example, taking of listed species that is otherwise prohibited may be permitted under Section 10 if various provisions are met, including: (1) such taking is incidental to and not the purpose of the otherwise lawful activity, (2) the taking will be minimized and mitigated to the maximum extent practicable, and (3) the taking will not appreciably reduce the likelihood of the survival and recovery of the species in the wild (e.g., 'jeopardize' the continued existence of the

\footnotetext{
* Corresponding author. Present Address: US Geological Survey, Alabama Cooperative Fish and Wildlife Research Unit, School of Forestry and Wildlife Sciences, Auburn University, Auburn, AL 36849, United States. Tel.: +1 3348449231.

E-mail address: cmcgowan@usgs.gov (C.P. McGowan).

1 Present address: P.O. Box 1326, Grand Marais, MN 55604, United States.
}

species) (50 CFR $\S 17.22$ and $\S ~ 17.32$ ). Similarly, incidental taking associated with federal agency actions may be permissible under US-ESA Section 7, provided the agency assures that the impacts of the action, including any cumulative effects and any reasonable and prudent measures necessary to minimize such impacts, will not jeopardize the species (50 CFR $§$ 402.12).

The concept of authorized take is widely used in endangered species legislation in other industrialized nations as well. In the European Union, the Bern Convention on the Conservation of European Wildlife and Natural Habitats prohibits destruction of protected species, but permits exceptions in order "to prevent serious damage to crops, livestock, forest, fisheries, water and other forms of property..." as long as "the exception will not be detrimental to the survival of the population concerned" (Convention on the Conservation of European Wildlife and Natural Habitats, Bern, 19.IX.1979, Article 9). The Australian Environment Protection and Biodiversity Conservation Act (Australian Environment Protection and Biodiversity Conservation Act 1999 No. 91) and the Canadian Species at Risk Act (Canada Wildlife Act 1985 Revised Statues of Canada, chapter W-9, Section 1) contain similar 
language for exceptions to endangered species protections. Japan's endangered species protection law, adopted in 1992, also allows the government to issue permits to individuals for exceptions to the prohibitions of the law (Takahashi, 2009).

Despite the prevalence of incidental take allowances in endangered species legislation there have been few examinations of the incidental take concept, as applied to endangered species, in the scientific literature (McGowan and Ryan, 2009), with one notable and important exception. The US Marine Mammal Protection Act of 1972 (MMPA) prohibits the taking of marine mammals, but allows for incidental take provided it is "negligible" (16 USC 1371(a)(5)(A)), or, for commercial fisheries, provided it is less than the Potential Biological Removal (PBR) and approaching zero mortality (16 USC 1387). A quantitative interpretation of PBR is provided in the Act (16 USC $1362(20)$ ), and is based on a substantial body of scientific literature, the central point of which is that compensation allows sustainable take (Wade, 1998; Taylor et al., 2000). Nevertheless, the application of these concepts more broadly to take of endangered species has not been investigated.

In this paper, we focus on the US-ESA because documentation of government implementation of this policy is abundant (e.g., USFWS, 1998). But, the concepts we discuss are applicable to all endangered species laws that contain incidental take allowances. Inherent in the concept of incidental take is the notion that endangered populations can withstand a limited harm to individuals without affecting the population or species as a whole - in other words, the population can compensate for the individual taking (Czech and Krausman, 1998).

\subsection{Compensation theory}

Compensation occurs when harm to or taking of individual animals is buffered to some extent at the population level (Boyce et al., 1999). Compensation can come in many forms: it can be behavioral or demographic; it can occur through changes in reproduction, survival, or dispersal; and it can be immediate or delayed. Behavioral responses, such as habituation by individuals to human disturbance, could be a mechanism for animals to buffer the potentially negative effects of human disturbance (Whitacker and Knight, 1998). In the case of habitat destruction, individuals may be able to move to other non-degraded areas in response to some human alteration to their habitat, which could compensate for habitat destruction as long as there are no density-dependent effects created in the newly settled non-degraded habitat.

Demographic compensation can theoretically act via increases in reproductive success or decreases in juvenile or adult mortality (Nichols, 2000; Williams et al., 2002), and can occur under any circumstances where natural density dependence is alleviated by some human action (Sinclair and Pech, 1996). Density-dependent demographic processes will induce partial compensation and are the basis of some sustainable harvest schemes (Runge et al., $2004,2009)$. The fundamental notion is that take of individuals reduces the population size, freeing up resources that other individuals can use to increase their survival and reproductive rates, and thus the reduction in the population is offset to some degree by compensatory increases in the growth rate of the population. In some fields, the term compensation is used to refer to full compensation, a case when the individual losses are not felt at all at the population level; such compensation requires special demographic mechanisms (Boyce et al., 1999). This use of the term is not ubiquitous, however, so some care is required to understand what a particular writer means. In this paper, we use compensation in the broader sense that includes partial compensation.

Often compensation is lagged. It may occur across years, for instance, if population productivity increases following an anthropogenic mortality event in the previous year because fewer individuals are competing for limited breeding territories, food, or other resources. Compensation can occur across seasons if density dependence is seasonal and occurs after take. For example, fall harvest mortality can be compensated if natural over-winter mortality is decreased because fewer individuals are competing for limited winter food resources. Demographic compensation can also be fairly immediate and occur within seasons if some density dependence is immediately alleviated and the remaining individuals in the population have higher productivity or survival. Compensation can also occur over space if localized anthropogenic mortality somehow alleviates demographic density dependence elsewhere.

One of the most commonly discussed forms of compensation is compensatory mortality, where seasonal density-dependent mortality is alleviated through some human-caused mortality such as harvest (Nichols, 2000). Compensatory mortality theory in predicated on the notion that a population may annually produce more individuals than the environment can sustain and when the population exceeds that capacity, competition for resources and reduced survival ensue (Trost, 1987; Sinclair and Pech, 1996; Nichols, 2000; Williams et al., 2002). Compensatory theory postulates that anthropogenic mortality alleviates natural densitydependent mortality and that the effects of harvest on population size and growth are moderated (Trost, 1987; Sinclair and Pech, 1996; Nichols, 2000). In the extreme, full compensation can arise through some mechanisms, like a population bottleneck above which excess individuals are culled. Conversely, additive mortality occurs when a population does not produce a doomed surplus or cannot compensate for harvest mortality via alleviation of some natural density dependence; with additive mortality, natural mortality and reproductive rates do not change in response to population density to compensate for the added mortality (Williams et al., 2002).

Density-dependent population dynamics are difficult to measure and study in wildlife populations and annual fluctuations in timing and magnitude of density-dependent factors are highly probable (Sinclair and Pech, 1996). Thus the ability of a population to compensate for anthropogenic mortality or other negative factors could also vary annually and seasonally.

\subsection{Compensation and incidental take}

We argue that regulatory 'incidental take' is essentially the concept of demographic compensation applied to protected species at risk of extinction. Under US-ESA, compensation theory is especially relevant to incidental take provision 3 and, to a lesser extent, provision 2 described above. The process of authorizing incidental take involves first determining whether an action will affect any individuals of an endangered species adversely (e.g., cause 'take'), and if so, that this take will not rise to unacceptable levels of demographic and population effects (i.e., under the US-ESA, the take will not cause jeopardy). If individuals are harmed or taken, the population could theoretically absorb those effects through compensatory mechanisms. We argue that the statement in legislation allowing take of a protected species as long as the take "will not reduce appreciably the likelihood of survival and recovery of the species in the wild" (provision 3 ) implies that protected populations have at least some capacity to compensate for take, or rather that, authorization of take should only occur if the evidence for that compensation is compelling. Further, the statement that take "will be minimized and mitigated to the maximum extent practicable" (provision 2) implies that managers could potentially create compensation opportunity though mitigation actions that increase population growth to counteract take. Even in situations where permitted take applies to habitat destruction or individual "harassment" without direct mortality, the implication is that 
any individual effects would be compensated through population demographics or behavioral responses. For example, for a one-time habitat destruction event, a disturbance-dependent species might initially suffer reproductive failure when a habitat patch is first disturbed (e.g., timber is harvested or a river corridor is flooded) but experience elevated productivity in the years following the disturbance. The central question related to take of an endangered species should be: 'Does this species have the reproductive capacity or density-dependent mortality to buffer the effects of incidental take such that the population's survival and recovery are not affected?'

The concept of compensation is the basis of sustainable harvest of most game species. Harvested game species tend to have high reproductive rates and correspondingly high juvenile mortality, hence 'surplus' production consistent with the compensatory mortality paradigm (Baldassarre and Bolen, 1994; Williams et al., 2002). The relationship between hunting mortality and annual survival has been studied extensively for mallards (Anas platyrhynchos) in North America (Burnham et al., 1984; Trost, 1987; Nichols, 2000). For example, Nichols et al. (2007) presented evidence for both compensatory and additive mortality in continental mallard populations. Gibson et al. (in press) recently concluded that compensation did not occur for hunting mortality in a harvested population of sage grouse (Centrocercus urophasianus), whereas Devers et al. (2007) concluded that ruffed grouse (Bonasa umbellus) populations in the Appalachian region did compensate for harvest mortality.

Applying the compensation paradigm to endangered species management sounds like a reasonable application of classical wildlife management concepts that attempt to balance resource uses in the short and long terms by allowing (or even 'maximizing') harvest of 'excess' animals while sustaining persistent populations over time. However, compensatory mortality and natality are theoretical concepts that do not apply to all species in the same way (Sinclair and Pech, 1996; Boyce et al., 1999; Xu et al., 2005). Compensation probably varies across species and years, and likely only for species with high reproductive capacity (Kokko et al., 2001; Poysa et al., 2004). Czech and Krausman (1998) discussed the applicability of the compensation paradigm to endangered species and questioned whether compensation was a safe and reasonable assumption for incidental take and endangered species management.

Generally, rare and threatened species do not have excess reproduction, but rather have high adult survival and low annual productivity (Rabinowitz, 1981; Purvis et al., 2000). Additionally many have small population sizes and currently declining population trends, further suggesting limited capacity for compensation. Small populations (i.e., highly endangered species) may have their natural compensatory mechanisms undermined by high levels of environmental and demographic stochasticity. For example, one unexpectedly bad year for reproduction due to severe drought may be compounded by incidental take of adult breeders which at larger population sizes would have been compensated for by density-dependent non-breeding season mortality. We argue that without compensation these populations cannot sustain harm from incidental take without adverse population effects unless take is fully offset by mitigation designed to create compensation opportunity (Rohlf, 2001).

In this paper we use a population simulation model to examine how density-dependent mortality might alleviate the negative effects of take on threatened populations. McGowan and Ryan (2009) used a population model to show that piping plovers are in decline and that permitted take of plover eggs in the Missouri River due to US Army Corps of Engineers (USACE) activities further depressed population growth and increased extinction probability. We modified McGowan and Ryan's (2009) model by adding a density-dependent function to post-fledging winter survival to examine how potential levels of take affect population dynamics with and without density dependence. We further examine whether populations in decline have less capacity for compensation than do stable or growing populations. Our goal is to investigate and understand the ecological basis for the legislative directives of incidental take and to use ecological theory to improve incidental take management and decision making for protected species in the future.

\section{Methods}

McGowan and Ryan (2009) used a population model to assess the effect of permitted and probable take actions in the Missouri River on piping plover population viability in the Great Plains. They used a two-stage population model that annually split the population into three habitat types (McGowan, 2008; McGowan and Ryan, 2009) in order to isolate the Missouri River habitat, where take was permitted, from the rest of the population. McGowan and Ryan (2009) give a full description of the simulation model; the basic population model, based on a pre-breeding census, was as follows:

$N_{t+1}=\left(P_{w, t} F_{w, t}+P_{M, t} F_{M, t}+P_{r, t} F_{r, t}\right) N_{t} S_{i, t}+N_{t} S_{a, t}$,

where $N$ is the total population size, $t$ is the annual time step, $P_{w}, P_{M}$, and $P_{r}$ are the proportions of the population breeding in alkali wetlands $(w)$, Missouri River $(M)$ and other river $(r)$ habitats, $F_{w}$ is the fecundity at wetland sites (average number of females fledged per breeding female, mean $=0.56), F_{M}$ is the fecundity at Missouri River sites, and $F_{r}$ is the fecundity at other river habitat sites. $S_{i}$ is annual survival of first-year birds (mean $=0.48$ ), and $S_{a}$ is the annual survival of adult birds (mean $=0.737$ ). This was a female-only model with a simple ceiling type density dependence function limiting the population to 10,000 individual females. Though density dependence and habitat limitation almost certainly exist for this population we do not have estimates for those relationships. Following the precedent of McGowan and Ryan (2009) we used a simple ceiling type density dependence function to limit population growth beyond an arbitrarily high ceiling to prevent unchecked exponential population growth. Further studies and analyses on habitat limitations to population growth may benefit management efforts for this species and also provide insight on opportunities for demographic compensation in this population.

We created a hierarchical loop structure where the population was replicated 10,000 times in the outer loop (the iteration loop) and projected 30 years into the future in the inner loop (the annual loop). The model included both temporal and sampling variation in survival and fecundity parameters (White, 2000; McGowan and Ryan, 2009) where sampling variance was included in the iteration loop of the simulation model according to the methods described by White (2000) and McGowan et al. (submitted for publication). This approach was needed to accurately reflect uncertainty regarding population demographics.

In the model the population redistributed across the three habitat types at random with no inter-year correlations. No published studies present information on settlement patterns or density-related habitat selection; thus, we used a stochastic process for assigning habitat distributions based on reported proportions of the breeding population that nest in each habitat type (Haig et al. 2005, Larson et al., 2002; McGowan and Ryan, 2009). Survival of first-year birds and adult birds was the same across habitats (there is no empirical basis for differing survival across habitats), but fecundity differed. Larson et al. (2002) and McGowan and Ryan (2009) reported large differences in breeding success between alkali wetlands and riverine habitats. Fecundity in the Missouri River was modeled according to the recommendations of Noon and 
Sauer (1992) with some modifications to account for precocial birds and to allow for incidental take of eggs and chicks. Fecundity was calculated as follows:

$F_{M}=\frac{\left(\left(\left(N_{t} P_{M, t} R_{t} C_{t}\right)-T_{e}\right) S_{n, t}-T_{c}\right) S_{c, t}}{\left(N_{t} P_{M, t}\right)}$

where $R$ is the number of nests per breeding female (mean $=1.2$ ), $C$ is the mean clutch size (mean $=3.4$ eggs), $T_{e}$ is the number of eggs taken by USACE actions $\left(T_{e}=p_{e}\left(N_{t} P_{M, t} R_{t} C_{t}\right)\right.$, where $p_{e}$ is the proportion of eggs taken), $S_{n}$ is the nest survival rate (survival to hatching, mean $=0.52), T_{c}$ is the number of chicks taken by USACE activities (for these simulations $T_{c}$ was set to 0 ), and $S_{c}$ is the chick survival rate (survival to fledging, mean $=0.16$, McGowan et al., 2009). The USACE is permitted, under a series of biological opinions issued by the USFWS, to take on average $9.2 \%$ of eggs laid in the Missouri River annually with a maximum of $42 \%$ or 294 eggs in any single year (whichever is smaller); additional take of chicks was not addressed in the biological opinion (USFWS, 2000, 2003; McGowan and Ryan, 2009). Fecundity at other river habitats was modeled the same way, but without the incidental take subtractions and with a lower probability of survival to hatching $\left(S_{n}=0.33\right.$, McGowan and Ryan, 2009). McGowan and Ryan (2009) ran a series of simulations with varying levels of take and through regression analyses estimated that permitted take was significantly reducing population growth rate and projected abundance 30 years in the future, as well as significantly increasing the probability of quasi-extinction. Their model assumed additive mortality due to take caused by USACE actions (McGowan and Ryan, 2009).

If natural mortality is density-dependent and follows incidental take in the annual cycle it should allow the population to compensate for at least some harmful effects of take (Kokko et al., 1998; Xu et al., 2005). To investigate these potential compensatory mechanisms, we modified the model to include a density-dependent negative linear logistic function on first-year survival, so that as winter population abundance increased, first-year survival decreased. Winter survival of juveniles declined as total population abundance after the breeding season increased, as follows:

$S_{i, t}=\frac{\exp \left(\alpha-\beta\left(N_{t}+N_{t}\left(P_{w} F_{w}+P_{M} F_{M}+P_{r} F_{r}\right)\right)\right)}{1+\left(\exp \left(\alpha-\beta\left(N_{t}+N_{t}\left(P_{w} F_{w}+P_{M} F_{M}+P_{r} F_{r}\right)\right)\right)\right)}$,

where the regression parameter $\alpha$ was set to 0.1 and $\beta$ was set to $5.0 \times 10^{-4}$. Although there are no empirical estimates of this density-dependent survival relationship, we were able to choose $\alpha$ and $\beta$ values for which the plots of the resulting first-year survival encompassed the variability of published first-winter survival estimates for this species (Ryan et al., 1993; Larson et al., 2000, 2002). Using the baseline nesting, clutch size, and survival rates cited above, we simulated the population with and without density dependence under a variety of incidental take levels ( $0-14 \%$ of Missouri River eggs).

All previous models of the piping plover population in the Great Plains estimated between 3\% and 12\% annual declines (Ryan et al., 1993; Plissner and Haig, 2000; Larson et al., 2002; McGowan and Ryan, 2009). If the population is, in fact, in such rapid decline then either: (1) it is not producing a "doomed surplus" annually and therefore cannot compensate for incidental take, (2) the population can sustain take and is just in a temporary transition to a lower equilibrium point, or (3) the existing take already exceeds the capacity for compensation. It is not the purpose of this paper to discern those hypotheses, so to test the applicability of the compensation paradigm to stable as well as declining populations, we simulated another hypothetical piping plover population that was approximately stable in size over time and might be able to compensate for take. We increased the mean annual adult survival
$\left(S_{a}\right)$ from $\sim 0.737$ baseline to $\sim 0.832$, and the mean number of nests per female $(R)$ from $\sim 1.2$ baseline to $\sim 1.45$ nests per female.

Thus, in all, we ran four different permutations of the population simulations: (1) low annual adult survival with no density dependence, (2) low annual adult survival with density-dependent juvenile survival, (3) high annual adult survival with no density dependence, and (4) high annual adult survival with densitydependent juvenile survival. Within each of the four scenarios, we applied eight levels of annual egg take $\left(p_{e}=0,0.02,0.04,0.06\right.$, $0.08,0.10,0.12$, and 0.14 of the eggs laid in the Missouri River). We replicated each simulation 10,000 times and simulated 30 years into the future. We chose a 30-year projection time frame following McGowan and Ryan (2009). We argue that a 30-year time frame balances the potential interest in long-term accumulating effects of incidental take against the increasing uncertainty in model projections as duration of the simulation increases (Morris and Doak, 2002). The 32 scenarios ( 4 models $\times 8$ levels of egg take) were modeled so that each of the eight levels of egg take would be applied to the same values of the survival and habitat distribution parameters taken from the sampling distributions. Juvenile survival differed across take scenarios because it was modeled as a density-dependent parameter in two of the four models, and fecundity differed $\left(F_{M}, F_{r}\right)$ across take scenarios, because that parameter was dependent on population size and take amount in our model (see Eq. 2). Thus, for each year in each replication we simulated 32 different population and incidental take scenarios. This approach induced a parallel structure to the simulation that greatly reduced variation across simulated scenarios; the resulting patterns in the simulated data required minimal statistical interpretation. All simulations were done in program R ( $\mathrm{R}$ Core Development Team, 2009).

Similar to McGowan and Ryan (2009), we used regression models to examine the effect of increasing egg take rates on the probability of quasi-extinction at 30 years (probability of falling below a 100 female abundance threshold at any time during the 30 years). If compensation was alleviating the harmful effects of all take we would expect no significant relationship between quasi-extinction probability and take. We also examined the percent decline in abundance due to increasing take by comparing abundance at 30 years for each level of take to a simulation with no take. If take is compensated by density-dependent juvenile survival we would expect little or no decline in abundance, or if some low levels of the take were compensated by the density-dependent post-fledging mortality we would expect $\sim 0 \%$ decline under the low take rate simulations.

\section{Results}

In all the simulations except the scenario with high survival and no juvenile survival density dependence, the median population abundance declined over 30 years even when no incidental take was applied. The scenarios with low survival and density-dependent juvenile survival predicted the greatest declines and highest extinction probabilities (quasi-extinction $\sim 21 \%$, Fig. 1a), followed by the scenarios with low survival and no density dependence (quasi-extinction $\sim 17 \%$, Fig. 1a). The scenarios with high adult survival had very low quasi-extinction probabilities, between $0.7 \%$ and $1.0 \%$ (Fig. 1b). Regression analysis showed that scenarios with low adult survival and no density dependence had significantly positive associations between modeled egg take and resulting quasiextinction probability $\left(\beta_{1}=0.09, \quad F=481.2, \quad p \ll 0.01, \quad d f=6\right.$, $r^{2}=0.98$, Fig. 1a). Similarly, scenarios with low adult survival with density-dependent juvenile survival had a positive association between egg take and quasi-extinction probability $\left(\beta_{1}=0.11, F=53.5\right.$, $p \ll 0.01, d f=6, r^{2}=0.88$, Fig. 1 a) and so did scenarios with high adult survival and no density dependence $\left(\beta_{1}=7.7 \times 10^{-3}\right.$, 

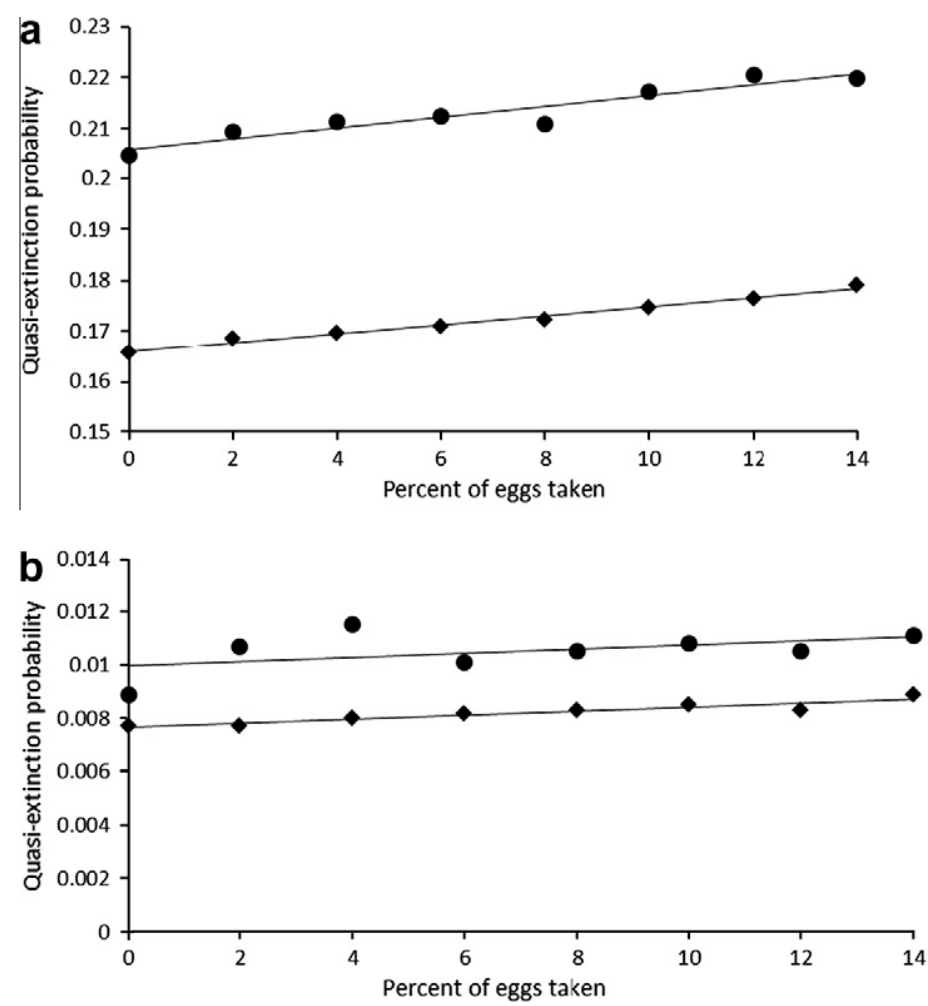

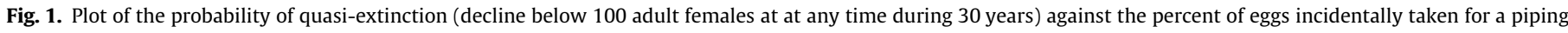

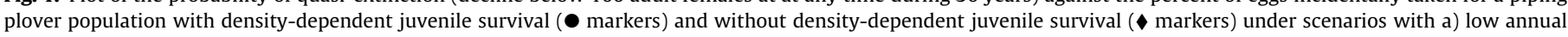
adult survival and b) high annual adult survival.

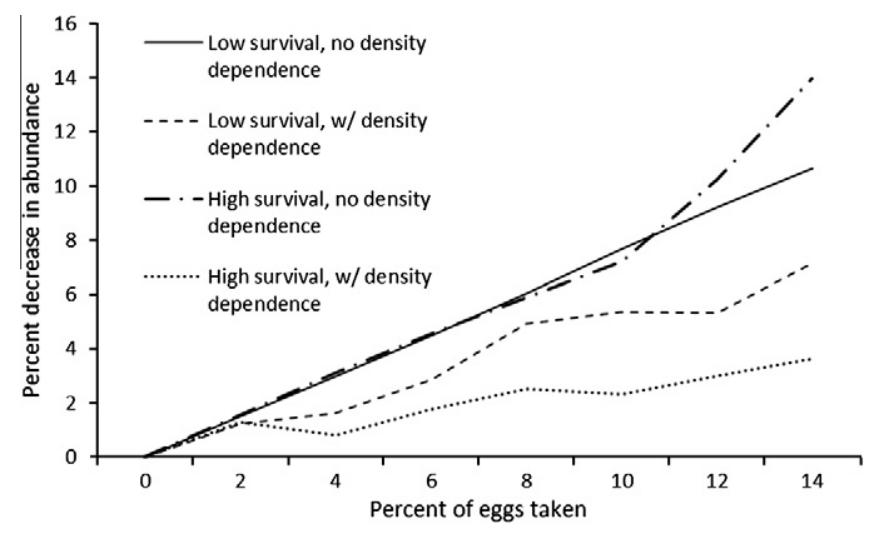

Fig. 2. The simulated percent decline in median abundance at 30 years, relative to the no-take scenario, under $0 \%$ (baseline), $2 \%, 4 \%, 6 \%, 8 \%, 10 \%, 12 \%$, and $14 \%$ of eggs incidentally taken for piping plovers in the Great Plains, with low or high adult survival, and with or without density-dependent juvenile survival.

$F=45.0, p \ll 0.01, d f=6, r^{2}=0.86$, Fig. 1b). The scenarios with high adult survival and density-dependent juvenile survival showed no significant association between percent of eggs taken and quasiextinction probability $\left(\beta_{1}=0.007, F=1.7, p=0.23, d f=6, r^{2}=0.09\right.$, Fig. 1b).

The scenarios without density-dependent juvenile survival showed the greatest percent decline in abundance as egg take rates increased (Fig. 2). The scenarios with high adult survival and density-dependent juvenile survival had only a 3.6\% decline in abundance as take increased from $0 \%$ to $14 \%$ of eggs laid (under $T_{0}$, $N_{t=30}=1054$ and under $T_{14 \%}, N_{t=30}=1016$, Fig. 2 ), whereas, the scenario with low adult survival and no density dependence on juvenile survival had a $10.7 \%$ decline as take increased from $0 \%$ to $14 \%$ of eggs laid (under $T_{0}, N_{t=30}=712$ and under $T_{14 \%}, N_{t=30}=636$, Fig. 2).

\section{Discussion}

Our simulations show that when density dependence exists and the piping plover population is not rapidly declining, some levels of incidental take might be compensated. For the simulations with a nearly stable population and post-fledging density-dependent survival, the regression model showed no relationship between egg take and quasi-extinction probability. Simulations with no density-dependent juvenile survival and/or with declining population trends had significant positive relationships between quasi-extinction probabilities and egg take rate.

The simulations lacking density-dependent juvenile survival also had the greatest percent decline in abundance due to increases in egg take. Though final abundance declined with increasing egg take for the simulations with density dependence, these declines were small compared with the declines observed under the scenarios lacking density dependence. Furthermore, for the high survival and density dependence scenarios, those declines in abundance did not translate into increased quasi-extinction probabilities.

From our simulation analyses, we can conclude that if densitydependent juvenile mortality exists for piping plovers in the Great Plains, and the populations were not rapidly declining, some level of egg take might be compensated and not affect the probability of quasi-extinction. However, a brief examination of the annual and life cycles of piping plovers suggests that few opportunities for compensation exist. The species exhibits high within-season survival during the winter on the Gulf Coast in Texas (Drake et al., 2001). Birds forage in small feeding flocks during the non-breeding season (Zonick, 2000), suggesting a non-limiting food source during that time period (Brown, 1964) and therefore food-mediated 
density dependence is unlikely. There have been no reported density related disease out-breaks for this species. Adams et al. (2003) studied records of carcass cleanup efforts following botulism epidemics in shorebirds and no piping plover carcasses were reported. Little is known about the migration route of piping plovers in the Great Plains, but it is probable that most birds make the migration to the Gulf Coast in one non-stop flight in most years (Haig and Elliott-Smith, 2004). If migration flights are non-stop, then most mortality during this time period would likely be caused by largely density-independent, weather-related factors. Pre-migratory body condition could affect an individual's survival during migration, and that could be a function of food availability and density-dependent, conspecific competition in breeding or staging habitats (Alerstam and Lindstrom, 1990). There also may be mortality during migration due to raptor predation, which could be a densitydependent factor. However, these factors are considered minor contributors to mortality in piping plovers (Haig and Elliott-Smith, 2004). Piping plovers may also experience some limited densitydependent mortality during the breeding season and so it is possible that the population might be able to compensate for low levels of incidental take of eggs and chicks during the breeding season.

In summary, the known ecology of piping plovers suggests little opportunity for compensation, although there is considerable uncertainty about certain periods of the annual cycle. If there is capacity for compensation, we think it is most likely in first-year survival or in density-dependent reproduction. Estimation of first-year, over-winter survival in relation to population density or overall abundance over a number of years would directly assess the potential for piping plovers to compensate for incidental take of eggs. Studies of productivity as a function of population size would also be valuable. Alternatively, an adaptive management approach with competing population models (one with densitydependent juvenile mortality and one without) could be used to learn about system function while allowing take to proceed cautiously (Nichols et al., 2007).

Modeling efforts predict that this population is likely in rapid decline (Ryan et al., 1993; Plissner and Haig, 2000; Larson et al., 2002; McGowan and Ryan, 2009). It is likely that either annual survival or productivity is already too low to sustain the population without intense management (Larson et al., 2003). If this is the case, then either the population is not capable of producing a surplus, or that surplus has already been exceeded by existing take; either way, it is unlikely the population could compensate for additional mortality caused by incidental take. For the rapidly declining populations in our simulations, any potentially compensatory capabilities of the population were overwhelmed and obfuscated by low adult survival rates or overall low productivity. However, recent efforts to estimate population size for piping plover have indicated substantial population increases in the Great Plains since 2001, which means that there may indeed be compensation opportunities (Elliott-Smith et al., 2009).

Intensive management and protection efforts are ongoing for piping plovers throughout the Great Plains, and it is possible that any compensatory capabilities in this population are being created by predator management efforts elsewhere in the range. Such conditions have the potential to create conflicts amongst agencies and partners where one agency is investing time and money to protect nests and improve population productivity while another is seeking permits to destroy eggs and potentially cancel out other conservation efforts. Perhaps such competing efforts should be considered as part of incidental take assessments and ongoing off-site management could be considered as mitigation and identified in incidental take permits under provision 2 (discussed in the Section 1 of this paper).

Our primary goal for the piping plover simulations was to explore and discuss the role and implications of compensation in incidental take asssessment, not necessarily to affect management of piping plovers in the Great Plains. The metrics of extinction and quasi-extinction probability match well with the "probability of survival in the wild" language used in endangered species protection legislation (McGowan and Ryan, 2010). The regression slope parameters from the analyses presented herein reflect relatively small increases $(<2 \%)$ in quasi-extinction probability in relation to increases in incidental take rates. We make no judgments as to whether such increases in quasi-extinction probability would be large enough to constitute jeopardy under current regulations for implementing the US-ESA, e.g., enough to "reduce appreciably" the likelihood of survival and recovery in the wild (50 CFR $\S$ 402.02). The USFWS and National Marine Fisheries Service have not defined a level of increase in extinction risk that would be "appreciable" enough to trigger jeopardy. If the law is interpreted to mean that some increase in extinction probability is below an appreciable threshold and, thus, acceptable, then demographic compensation is not necessary for incidental take to avoid jeopardy and be authorized. However, this interpretation requires the application of some standard or threshold for acceptable increases in extinction probability, which may cumulatively degrade species' status over time (Rohlf, 2001; Ruhl, 2004; Wood, 2004). An interpretation that jeopardy means no increase in extinction risk ('no further harm') requires no normative thresholds (Wood, 2004), but this definition relies strongly on the compensation concept since incidental take could only be authorized if it is fully compensated.

Further, the goal of the US-ESA is species recovery, which typically means increasing population sizes and distribution. So any population productivity that is 'excess' in terms of local population stability could be conserved for population growth and expansion rather than permitted as incidental take. Here the policy judgment is how much take appreciably reduces the likelihood of recovery.

Notwithstanding these possible alternative interpretations of the US-ESA jeopardy language, we argue that the compensation paradigm is the inherent yet largely unacknowledged basis for the incidental take allowances of many endangered species protection laws. As we have illustrated with the piping plover example, decision makers need to consider a species' ability to compensate for any proposed incidental take. Such an analysis should consider the seasonality of take and how it fits into the annual cycle of the species being managed (Kokko and Lindstrom, 1998; Boyce et al., 1999; Kokko et al., 1998; Xu et al., 2005). If the incidental taking occurs after the majority of density-dependent mortality has happened in the annual cycle, the compensation will be weaker and the take more likely to affect the probability of "survival in the wild." Or, if take of adults occurs before individuals have had the opportunity to breed in the annual cycle, take will also have a greater impact on the population than will take at other seasons (Kokko and Lindstrom, 1998; Boyce et al., 1999; Kokko et al., 1998; Xu et al., 2005). Take at different life-stages may also have different impacts on the population: take from life-stages with higher reproductive value would have greater effects on the population and require stronger density dependence to avoid population effects (McGowan, 2008). For example, taking adult piping plovers - the most important life stage in this species for population viability (Ryan et al., 1993; Larson et al., 2002) - would require high levels of compensatory mortality for the population to be buffered and the take to have no population effects. Lastly, it is important for managers to remember that environmental and demographic stochasticity tend to dampen population growth (Morris and Doak, 2002) and may undermine compensatory mechanisms, adding uncertainty to predictions and decision making (Goodman, 2002). Appropriate population models can be used to consider the effects of uncertainty and stochasticity on long-term population outcomes. 
With endangered species there is likely uncertainty about the existence and magnitude of density-dependent demographics and about the applicability of compensatory theory to any given species. Under these circumstances managers could apply the tools of structured decision making and adaptive management, using multiple system models (i.e., one with density dependence and one without) for decision making and follow-up monitoring of population response to begin learning about a population's capacity to compensate for incidental take (Nichols et al., 2007). The models and the monitoring would be case- and species-specific, but the general framework of adaptive management (using models to predict the effects of management actions and monitoring the system to measure the response) can be quite successful despite high uncertainty (Nichols et al., 2007, McGowan et al., in press). Though potentially costly, follow-up monitoring to evaluate the existence of (or strength of) demographic compensation or the impact of mitigation to create compensation opportunity could be important to understanding the species ecology and improving future incidental take decision making. If using a structured decision making or adaptive management approach to reduce uncertainty about the strength of compensation for incidental take decisions, we argue monitoring plans designed specifically to evaluate compensation should be an explicit part of the incidental permitting process.

Compensatory theory and its implications for population dynamics and endangered species management may not be limited to incidental take allowances. Demographic compensation might affect recovery feasibility and management strategies for achieving recovery. With piping plovers for example, in the Great Plains population much of the management and recovery effort is targeted at increasing productivity through nest and chick protection efforts. However if there is strong over-winter density dependence on first-year survival, efforts to increase productivity may have no net effect on population growth, abundance or recovery probability. Managers should consider the possible impacts of demographic compensation not only in the case of incidental take assessments but perhaps in many aspects of endangered species decision making and management.

In conclusion, wildlife managers and incidental take decision makers should consider the applicability of compensatory theory to each endangered species and each incidental take permit. Managers and decision makers should consider whether a species has the capacity to buffer incidental take through excess reproduction, or if the population likely experiences some density-dependent mortality after the take occurs. If none of these buffers are likely to exist naturally it may be possible to create compensation via mitigation in habitat management and species protection (e.g., reducing natural mortality), but careful assessment of compensatory capacity is warranted in any case.

\section{Acknowledgements}

We thank: The USFWS and the USGS for supporting this work financially; B. Gardner for assistance with R code; M. Larson, J.E. Lyons, S. Rikoon, F.R. Thompson III, and E. Zipkin for reviewing and helping to improve earlier versions of this manuscript; The editors and anonymous reviewers of this paper for their constructive input and efforts to improve this paper. Use of product or firm names does not imply endorsement by the US Government.

\section{References}

Adams, S.G., Conly, F.M., Gratto-Trevor, C.L., Cash, K.J., Bollinger, T., 2003. Shorebird use and mortality at a large Canadian lake impacted by Botulism. Waterbirds $26,1-12$.
Alerstam, T., Lindstrom, A., 1990. Optimal bird migration: the relative importance of time, energy and safety. In: Gwinner, E. (Ed.), Bird Migration: The Physiology and Ecophysiology. Springer, Berlin, pp. 331-351.

Baldassarre, G.A., Bolen, E.G., 1994. Waterfowl Ecology and Management. John Wiley \& Sons Inc., New York.

Boyce, M.S., Sinclair, A.R.E., White, G.C., 1999. Seasonal compensation of predation and harvesting. Oikos $87,419-426$.

Brown, J.L., 1964. The evolution of diversity in avian territorial systems. Wilson Bulletin 76, 160-169.

Burnham, K.P., White, G.C., Anderson, D.A., 1984. Estimating the effect of hunting on annual survival rates of adult mallards. Journal of Wildlife Management 48 350-361.

Czech, B., Krausman, P.R., 1998. Twelve faulty assumptions underlying the Endangered Species Act. Endangered Species UPDATE 15, 52-58.

Devers, P.K., Stauffer, D.F., Norman, G.W., Steffen, D.E., Whitaker, D.M., Sole, J.D. Allen, T.J., Bittner, S.L., Buehler, D.A., Edwards, J.W., Figert, D.E., Friedhoff, S.T. Guiliano, W.W., Harper, C.A., Ido, W.K., Kirkpatrick, R.L., Seamster, M.H., Spiker Jr., H.A., Swanson, D.A., Tefft, B.C., 2007. Ruffed grouse population ecology in the Appalachian Region. Wildlife Monographs 168.

Drake, K.R., Thompson, J.E., Drake, K.L., 2001. Movements, habitat use, and survival of nonbreeding piping plovers. Condor 103, 259-267.

Elliott-Smith, E., Haig, S.M., Powers, B.M., 2009. Data from the 2006 International Piping Plover Census. US Geological Survey Data Series 426.

Gibson, R.M., Bleich, V.C., McCarthy, C.W., Russi, T.L., in press. Recreational hunting can lower population size in greater sage-grouse. Studies in Avian Biology.

Goodman, D., 2002. Uncertainty, risk and decision making: 0the PVA example. In: Berkson, J.M., Kline, L.L., Orth, D.J. (Eds.), Incorporating Uncertainty into Fisheries Models. American Fisheries Society, Symposium 27, Bethesda, pp 171-196.

Haig, Susan M., Elliott-Smith, E., 2004. Piping plover. In: Poole, A. (Ed.), The Birds of North America Online. Cornell Laboratory of Ornithology, Ithaca. <http:// www.bna.birds.cornell.edu/BNA/account/Piping_Plover/> (retrieved from The Birds of North American Online database).

Haig, S.M., Ferland, C.L., Cutherbert, F.J., Dingledine, J., Goosen, J.P., Hecht, A. McPhillips, N., 2005. A complete species census and evidence for regional declines in Piping Plovers. Journal of Wildlife Management 69, 160-173.

Kokko, H., Lindstrom, J., 1998. Seasonal density dependence, timing of mortality, and sustainable harvesting. Ecological Modeling 110, 293-304.

Kokko, H., Lindström, J., Ranta, E., 2001. Life histories and sustainable harvesting. In: Reynolds, J.D., Mace, G.M., Redford, K.H., Robinson, J.G. (Eds.), Conservation of Exploited Species. Cambridge University Press, Cambridge, pp. 301-322.

Kokko, H., Poysa, H., Lindstrom, J., Ranta, E., 1998. Assessing the impact of springhunting on waterfowl populations. Annales Zoologici Fennicae 35, 195204.

Larson, M.A., Ryan, M.R., Root, B.G., 2000. Piping plover survival in the Great Plains: an updated analysis. Journal of Field Ornithology 71, 721-729.

Larson, M.A., Ryan, M.R., Murphy, R.K., 2002. Population viability of piping plovers: effects of predator exclusion. Journal of Wildlife Management 66, 361-371.

Larson, M.A., Ryan, M.R., Murphy, R.K., 2003. Assessing recovery feasibility for piping plovers using optimization and simulation. Wildlife Society Bulletin 31, 1105-1116.

McGowan, C.P., 2008. Incidental Take and Endangered Species Demography. Unpublished Ph.D. Dissertation. University of Missouri, Columbia.

McGowan, C.P., Millspaugh, J.J., Ryan, M.R., Kruse, C., Pavelka, G., 2009. Estimating survival of precocial chicks during the pre-fledging period using a 'catch curve' method and age based count data. Journal of Field Ornithology 80, 79-87.

McGowan, C.P., Runge, M.C., Larson, M.A., submitted for publication. Incorporating parametric uncertainty into population viability analysis models. Biological Conservation.

McGowan, C.P., Ryan, M.R., 2009. A quantitative framework to evaluate incidental take and endangered species population viability. Biological Conservation 142, 3128-3136.

McGowan, C.P., Ryan, M.R., 2010. Arguments for using population models in incidental take assessments for endangered species. Journal of Fish and Wildlife Management 1, 183-188.

McGowan, C.P., Smith, D.R., Sweka, J.A., Martin, J., Nichols, J.D. , Wong, R., Lyons, J.E. Niles, L.J., Kalasz, K., Brust, J., Klopfer, M., Spear, B., in press. Multi-species modeling for adaptive management of horseshoe crabs and red knots in the Delaware Bay. Natural Resource Modeling.

Morris, W., Doak, D., 2002. Quantitative Conservation Biology: Theory and Practice of Population Viability Analysis. Sinauer Associates, Sunderland.

Nichols, J.D., 2000. Evolution of harvest management for North American waterfowl: selective pressures and preadaptation for adaptive harvest management. Transaction of the North American Wildlife and Natural Resource Conference 65, 65-77.

Nichols, J.D., Runge, M.C., Johnson, F.A., Williams, B.K., 2007. Adaptive harvest management of North American waterfowl populations: a brief history and future prospects. Journal of Ornithology 148, S343-S349.

Noon, B.R., Sauer, J.R., 1992. Population models for passerine birds: Structure, parameterization and analysis. In: McCullough, D.R., Barrett, R.H. (Eds.), Wildlife 2001: Populations. Elsevier Applied Science, London, pp. 441-464.

Plissner, J.H., Haig, S.M., 2000. Viability of piping plover Charadrius melodus metapopulations. Biological Conservation 92, 163-173.

Poysa, H., Elmberg, J., Nummi, P., Sjoberg, G.G., Sjoberg, K., 2004. Ecological basis of sustainable harvesting: is the prevailing prardigm of compensatory mortality still valid? Oikos 104, 612-615. 
Purvis, A., Gittleman, J.L., Cowlishaw, G., Mace, G.M., 2000. Predicting extinction risk in declining species. Proceedings of the Royal Society of London 267, 19471952.

R Development Core Team, 2009. R: A Language and Environment for Statistical Computing. R Foundation for Statistical Computing, Vienna.

Rabinowitz, D., 1981. Seven forms of rarity. In: Synge, H. (Ed.), The Biological Aspects of Rare Plant Conservation. Wiley, New York, pp. 205-217.

Rohlf, D.J., 2001. Jeopardy under the Endangered Species Act: playing a game protected species can't win. Washburn Law Journal 41, 114-163.

Ruhl, J.B., 2004. The battle over Endangered Species Act methodology. Environmental Law (Florida State University College of Law) 34, 555-604.

Runge, M.C., Kendall, W.L., Nichols, J.D., 2004. Exploitation. In: Sutherland, W.J. Newton, I., Green, R.E. (Eds.), Bird Ecology and Conservation: A Handbook of Techniques. Oxford University Press, Oxford, UK, pp. 303-328.

Runge, M.C., Sauer, J.R., Avery, M.L., Blackwell, B.F., Koneff, M.D., 2009. Assessing allowable take of migratory birds. Journal of Wildlife Management 73, 556-565.

Ryan, M.R., Root, B.G., Mayer, P.M., 1993. Status of piping plovers in the Great Plains of North America: a demographic simulation model. Conservation Biology 7 . 581-585.

Sinclair, A.R.E., Pech, R.P., 1996. Density dependence, stochasticity, compensation and predator regulation. Oikos 75, 164-173.

Takahashi, M.A., 2009. Overview of the structure and the challenges of Japanese wildlife law and policy. Biological Conservation 142, 1958-1964.

Taylor, B.L., Wade, P.R., DeMaster, D.P., Barlow, J., 2000. Incorporating uncertainty into management models for marine mammals. Conservation Biology 14, 12431252.
Trost, R.E., 1987. Mallard survival and harvest rates: A reexamination of relationships. Transaction of the North American Wildlife and Natural Resource Conference 52, 265-284.

US Fish and Wildlife Service, 1998. Endangered Species consultation handbook. US Fish and Wildlife service and National Marine Fisheries Service, Washington, DC.

US Fish and Wildlife Service, 2000. Formal Biological Opinion of the Missouri River Main Stem Reservoir System. US Fish and Wildlife Service, Denver.

US Fish and Wildlife Service, 2003. Amendments to the 2000 Biological Opinion of the Missouri River Main Stem Reservoir System. US Fish and Wildlife Service, Denver.

Wade, P.R., 1998. Calculating limits to the allowable human-caused mortality of cetaceans and pinnipeds. Marine Mammal Science 14, 1-37.

Whitacker, D., Knight, R.L., 1998. Understanding wildlife responses to humans. Wildlife Society Bulletin 26, 312-317.

White, G.C., 2000. Population viability analyses: Data requirements and essential analyses. In: Boitani, L., Fuller, T.K. (Eds.), Research Techniques in Animal Ecology. Columbia University Press, New York, pp. 288-331.

Williams, B.K., Nichols, J.D., Conroy, M.J., 2002. Analysis and Management of Animal Populations. Academic Press, New York.

Wood, M.C., 2004. Protecting the wildlife trust: a reinterpretation of Section 7 of the ESA. Environmental Law 34, 605-645.

Xu, C., Boyce, M.S., Daley, D.J., 2005. Harvesting in seasonal environments. Journal of Mathematical Biology 50, 663-682.

Zonick, C.A., 2000. The Winter Ecology of Piping Plovers in Texas. Unpublished Doctoral Dissertation, University of Missouri, Columbia. 